\title{
Citomegalovirus: modalidades broncopulmonares de presentación
}

\author{
Dr. Julio Maggiolo M.', Dra. Lilian Rubilar O.', Dr. Ricardo Kogan A.,'2 \\ 1 Médico. Unidad Broncopulmonar. Hospital Exequiel González Cortés. \\ 2 Médico. Profesor Asistente de Pediatría. Campus Sur. Universidad de Chile.
}

\section{CYTOMEGALOVIRUS: DETAILED RESPIRATORY PRESENTATION}

Citomegalovirus (CMV), a herpesviridae, due to its high transmission rate, is endemic, with wide world distribution, especially in underdeveloped countries. CMV is an important pathogen agent during embryological period, being the commonest cause of TORCH syndrome. Due to its capability of infecting different organs, it can have a variety of clinical presentations. The more frequentand severe forms affect the respiratory, gastrointestinal, central nervous system and the retina. At the respiratory system CMV manifests in different ways, depending on age and immunological state of the patient. It produces interstitial pneumonias in immunocompromised host; but occasionally affects immunocompetent patients as a first trimester pneumonia, whooping cough like syndrome or chronic interstitial lung disease. The diagnostic method in use, the shell vial accelerated cultivation of samples obtain by bronchoalveolar lavage is both highly sensitive and specific. Treatment with ganciclovir has improved prognosis. The objective of this article is to show the different clinical presentations of CMV infection of the respiratory system in pediatric patients and the response to treatment.

Key words: Citomegalovirus, shell vial, bronchoalveolar lavage, ganciclovir.

\section{RESUMEN}

\begin{abstract}
Citomegalovirus (CMV) es un herpesviridae, endémico de amplia distribución mundial, debido a su alta tasa de transmisión, especialmente en países de bajo nivel socioeconómico. CMV es un importante agente patógeno en el período embrionario-fetal, siendo el principal agente etiológico del síndrome de TORCH. Por su capacidad de infectar diferentes órganos puede producir una variedad de cuadros clínicos, las formas más graves y frecuentes afectan al aparato respiratorio, gastrointestinal, sistema nervioso central y la retina. En el aparato respiratorio CMV se manifiesta de diversas maneras, dependiendo de la edad y del estado inmunológico del huésped. En inmunodeprimidos produce neumonías intersticiales graves; sin embargo, ocasionalmente afecta a individuos inmunocompetentes manifestándose como neumonía del primer trimestre, síndrome coqueluchoídeo o enfermedad pulmonar intersticial crónica. En la actualidad el método diagnóstico de elección es el cultivo acelerado de shell vial de muestra obtenida mediante lavado broncoalveolar, presenta alta sensibilidad y especificidad. El tratamiento con ganciclovir ha mejorado el pronóstico. El objetivo de este artículo es mostrar las diferentes formas de presentación clínica del CMV en el aparato respiratorio en pediatría y la respuesta al tratamiento utilizado.
\end{abstract}

Palabras clave: Citomegalovirus, shell vial, lavado broncoalveolar, ganciclovir.

\section{INTRODUCCIÓN}

Citomegalovirus (CMV) pertenece a la familia herpesviridae, de amplia distribución mundial, se estima que en promedio un $50 \%$ de la población es seropositiva, siendo mayor en países de bajo nivel socioeconómico(1,2). Sin embargo, sólo ocasionalmente produce enfermedad en inmunocompetentes ${ }^{(3)}$, es más importante durante el período embrionario-fetal, siendo el principal agente etiológico de infección congénita a nivel mundial(4,5) y en individuos con defectos en la inmunidad ${ }^{(6)}$.

Correspondencia: Dr. Julio Maggiolo M. Unidad Broncopulmonar. Hospital Exequiel González Cortés. Fonos: 2042254 - 7893228.

E-mail: maggiolojulio@gmail.com
CMV ha adquirido especial importancia por el aumento de los pacientes inmunodeficientes, debido a la epidemia de $\operatorname{SIDA}^{(7-11)}$ y por el uso de fármacos inmunosupresores en individuos que son sometidos a trasplantes de órganos sólidos, como médula ósea y riñón, entre otros ${ }^{(12,13)}$. Los niños portadores de leucemia y linfoma también son susceptibles a infecciones graves por CMV.

Por su capacidad de infectar diferentes órganos, puede producir diversos cuadros clínicos, las formas más graves y frecuentes afectan al aparato respiratorio, gastrointestinal, sistema nervioso central y la retina ${ }^{(1,2)}$. A nivel del aparato respiratorio en pacientes inmunocompetentes CMV puede producir neumonía trimestre del primer, síndrome coqueluchoídeo de evolución tórpida, y enfermedad pulmonar intersticial crónica $(E P I C)^{(14-17)}$, en cambio en individuos inmunocomprometidos la manifestación más frecuente es 
la neumonía intersticial grave(6-11). En la actualidad el cultivo acelerado de shell vial (SV) es el método diagnóstico de elección $^{(18-20)}$. El tratamiento con ganciclovir (GCV) ha mejorado el pronóstico ${ }^{(21-23)}$.

\section{CASOS CLÍNICOS}

Se efectúa un estudio descriptivo retrospectivo de 4 pacientes que manifestaban diferentes formas de presentación del CMV a nivel del aparato respiratorio, con un rango de I mes a 4 años de edad, entre los años 2004-2008. Esta serie estuvo constituida por 2 pacientes inmunocompetentes que se manifestaron uno como síndrome coqueluchoídeo y neumonía del primer trimestre y otro como síndrome coqueluchoídeo y EPIC y 2 inmunodeficientes, uno portador de trasplante renal que presentó una neumonía multifocal y otro niño $\mathrm{VlH}$ positivo que evolucionó con una neumonía intersticial grave (Tabla I).

El diagnóstico de enfermedad citomegálica fue hecho por la presencia de una infección respiratoria baja sugerente como neumonía del primer trimestre, síndrome coqueluchoídeo refractario o neumonía intersticial grave, tanto en inmunocompetentes como en inmunodeficientes, cultivo acelerado de shell vial positivo en lavado broncoalveolar (LBA) y orina, descartando otras etiologías y resultado terapéutico exitoso con el uso de ganciclovir ${ }^{(9)}$. A continuación se presentan los casos clínicos con mayor detalle.

\section{Caso clínico I}

Niña de I mes y 15 días, hija de padres sanos, parto de término eutócico y sin antecedentes mórbidos neonatales. Inicia síntomas respiratorios, en ausencia de fiebre, caracterizados por tos paroxística con cianosis peribucal y obstrucción bronquial leve. Es tratada con salbutamol en inhalador de dosis medida (MDI) y eritromicina por I 4 días pese a lo cual empeora progresivamente, siendo hospitalizada a los 2 meses de edad por insuficiencia respiratoria aguda. A su ingreso al servicio de urgencia destacaba ausencia de compromiso séptico, afebril, dificultad respiratoria moderada con una frecuencia respiratoria (FR) de 56x', retracción de partes blandas y saturación de oxígeno $\left(\mathrm{O}_{2}\right)$ de $88 \%$ que mejora a valores de $95 \%$ con 2 I/min de oxígenoterapia. La Figura la muestra la radiografía $(\mathrm{Rx})$ de tórax en proyección anteroposterior a su ingreso. La inmunofluorescencia indirecta (IFI) confirmó el diagnóstico de infección respiratoria aguda baja (IRAB) por virus respiratorio sincicial (VRS) y se planificó tratamiento con aporte de $\mathrm{O}_{2}$, salbutamol MDI y corticoides sistémicos.

Evolucionó afebril, con tos en accesos y cianosis peribucal, recibiendo tratamiento empírico por 14 días con eritromicina oral pese a inmunofluorescencia directa (IFD) para bordetella pertussis negativa. El laboratorio de apoyo demostraba hemograma, proteína $C$ reactiva (PCR) y electrolitos en sudor normales, 3 baciloscopias de contenido gástrico negativas, estudio inmunológico normal y ELISA para VIH negativa. Por persistir con requerimientos de $\mathrm{O}_{2}$ y haber progresión de los hallazgos radiológicos, el día 30 de evolución se decidió realizar fibrobroncoscopia para practicar lavado broncoalveolar (LBA), SV en LBA y orina, los que resultaron positivos para CMV. El resto de exámenes de diagnóstico microbiológico del LBA no confirmaron otras posibles etiologías, como microinmunofluorescencia (MIF) para la detección de IgM anti chlamydia trachomatis, tinción Gomot-Grocott y reacción de la polimerasa en cadena (RPC) para Pneumocystis jiroveci (PJ), el cultivo corriente y de hongos también resultaron negativos.

La Figura Ib corresponde al control radiológico después de 45 días de evolución, se observan escasos infiltrados intersticiales de carácter residual, momento en que además presenta mejoría clínica y es posible suspender la oxígenoterapia. Debido a esta favorable evolución no es tratada con antivirales, siendo dada de alta en buenas condiciones. Actualmente la paciente tiene 5 años de edad, presenta síndrome bronquial obstructivo (SBO) episódico infrecuente.

Tabla I. Característica clínicas, laboratorio y tratamiento

\begin{tabular}{|c|c|c|c|c|c|c|}
\hline Paciente & Edad & $\begin{array}{l}\text { Antecedentes } \\
\text { mórbidos }\end{array}$ & $\begin{array}{l}\text { Forma de presen- } \\
\text { tación }\end{array}$ & Diagnóstico clínico & $\begin{array}{l}\text { Diagnóstico labo- } \\
\text { ratorio }\end{array}$ & Tratamiento \\
\hline I & $\begin{array}{l}\text { I mes } \\
\text { I5 días }\end{array}$ & Sano & $\begin{array}{l}\text { Neumonía } \\
\text { Sd. coqueluchoídeo } \\
\text { evolución tórpida }\end{array}$ & $\begin{array}{l}\text { Neumonía primer } \\
\text { trimestre }\end{array}$ & $\begin{array}{l}\text { Shell vial en LBA y } \\
\text { orina } \\
\text { IFI VRS }\end{array}$ & Sin antiviral \\
\hline 2 & I mes & Sano & $\begin{array}{l}\text { SBO } \\
\text { Sd. coqueluchoídeo } \\
\text { evolución tórpida }\end{array}$ & $\begin{array}{l}\text { Neumonitis intersticial } \\
\text { crónica }\end{array}$ & $\begin{array}{l}\text { Shell vial en LBA y } \\
\text { orina } \\
\text { IFI VRS } \\
\text { IFD Bordetella. } \\
\text { Biopsia pulmonar }\end{array}$ & $\begin{array}{l}\text { Ganciclovir + } \\
\text { prednisona }\end{array}$ \\
\hline 3 & 4 años & Trasplante renal & Neumonía multifocal & Neumonía multifocal & $\begin{array}{l}\text { Shell vial en LBA y } \\
\text { orina }\end{array}$ & Ganciclovir \\
\hline 4 & 3 meses & $\mathrm{VIH}$ & $\begin{array}{l}\text { Neumonía intersticial } \\
\text { refractaria, diarrea } \\
\text { prolongada, } \\
\text { desnutrición }\end{array}$ & Neumonía grave & $\begin{array}{l}\text { Shell vial en LBA y } \\
\text { orina } \\
\text { RPC Pneumocystis } \\
\text { jiroveci en LBA } \\
\text { Antigenemia VIH }\end{array}$ & $\begin{array}{l}\text { Ganciclovir }+ \\
\text { cotrimoxazol }+ \\
\text { terapia antirretroviral }\end{array}$ \\
\hline
\end{tabular}

VIH: virus de la inmunodeficiencia humana; SBO: síndrome bronquial obstructivo; LBA: lavado broncoalveolar; IFI: inmunofluorescencia indirecta; VRS: virus respiratorio sincicial; IFD: inmunofluorescencia directa; RPC: reacción de la polimerasa en cadena. 


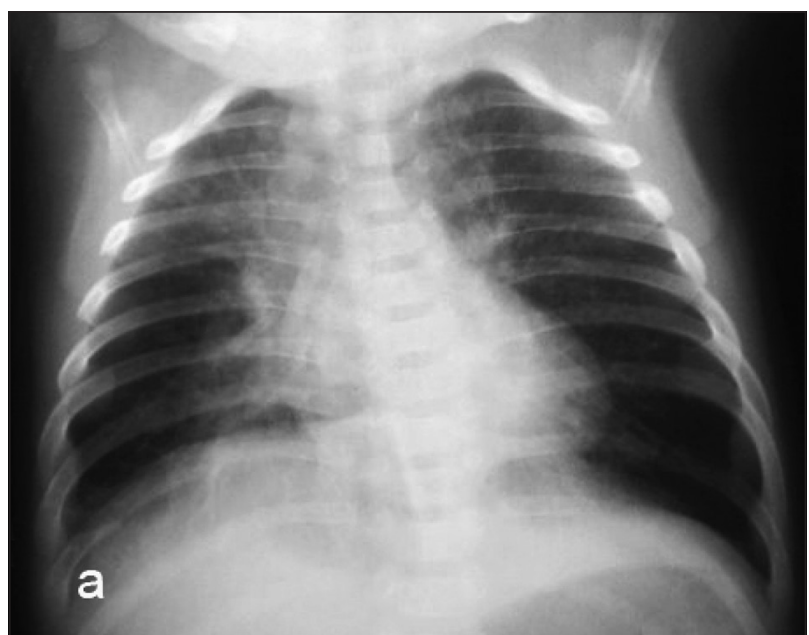

Figura Ia (paciente I). Rx tórax: extensos infiltrados intersticiales retículo-nodulares y lineales, que comprometen ambos campos pulmonares. Insuflación pulmonar moderada.

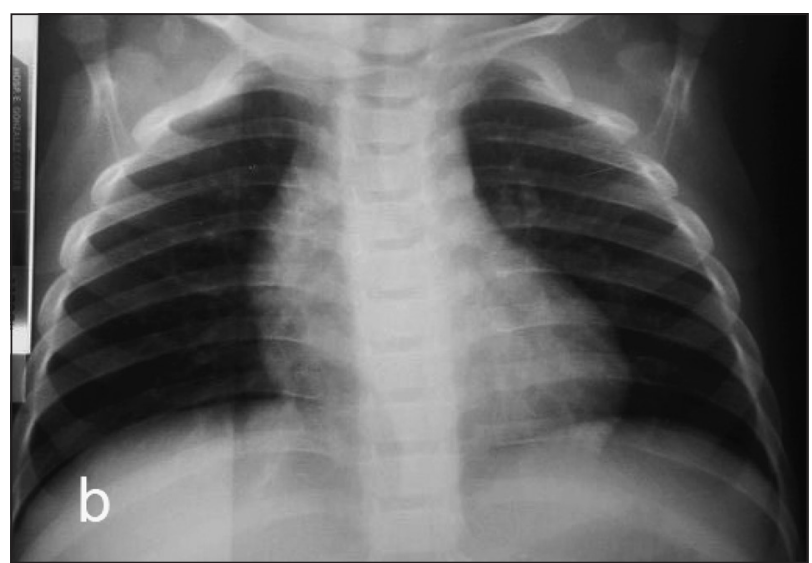

Figura Ib (paciente I). Rx tórax: escasos infiltrados intersticiales de carácter residual. Insuflación pulmonar moderada.

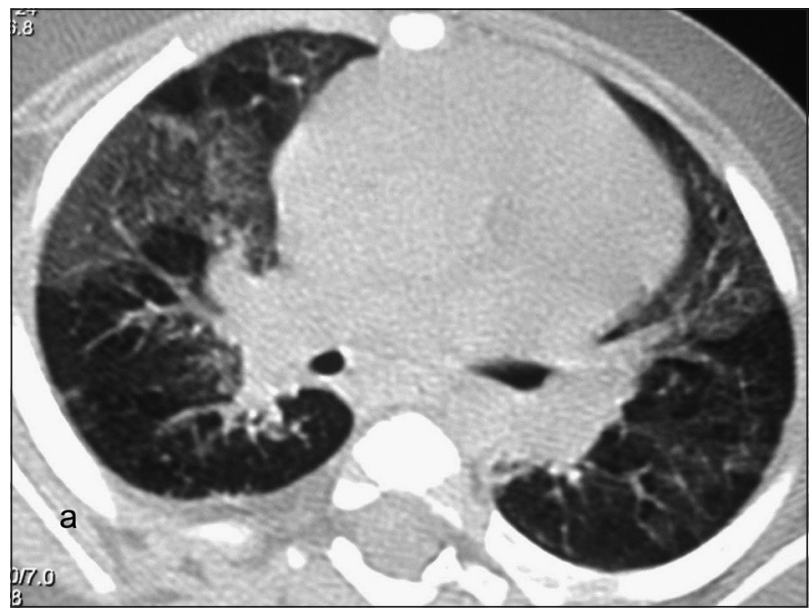

Figura 2a (paciente 2). TAC tórax alta resolución (nivel subcarinal): revela zonas de condensación, vidrio esmerilado y atrapamiento aéreo.

\section{Caso clínico 2}

Paciente femenino producto de séptimo embarazo normal, parto mediante cesárea por distocia de posición a las 36 semanas de gestación. Padres sanos. Sana hasta el primer mes de vida en que inicia un cuadro respiratorio caracterizado por tos en accesos, cianosis peribucal, dificultad respiratoria progresiva, ausencia de fiebre, estridor sibilante que evoluciona a insuficiencia respiratoria aguda parcial, es hospitaliza durante la segunda semana. Se practica IFD para Bordetella pertussis e IFI para VRS que resultan positivas, la $R \times$ de tórax revela un patrón intersticial difuso y atelectasias segmentarias. Recibe $\mathrm{O}_{2}$ por naricera, claritromicina durante 14 días, salbutamol MDI y corticoides sistémicos. Evoluciona tórpidamente por lo que se decide practicar mediante LBA en el día 24 de hospitalización, MIF para Chlamydia tachomatis, tinción de Gomot-Grocott y RPC para PJ, cultivo corriente y de hongos, todos resultan negativos, el estudio inmunológico fue normal y ELISA para $\mathrm{VIH}$ negativa. SV en secreción bronquial obtenida mediante LBA y en orina resultan positivos. La paciente es tratada con GCV 5 mg/kg por 6 semanas, sin embargo, persiste sintomática, con dificultad respiratoria, tos en accesos, crepitaciones bilaterales y dependencia de $\mathrm{O}_{2}$, con un patrón radiológico intersticial que se hace progresivo. Se efectúa una tomografía computada (TC) de tórax que muestra zonas de condensación, atrapamiento aéreo y otras en vidrio esmerilado (Figura 2a), por lo que se decide practicar biopsia pulmonar mediante videotoracoscopia asistida, que es informada como neumonitis intersticial crónica. Se inicia tratamiento con prednisona durante 8 semanas, observándose buena respuesta con desaparición de los crépitos, sin requerimiento de $\mathrm{O}_{2}$ adicional y mejoría de las imágenes radiológicas (Figura 2b), es dada de alta en buenas condiciones el día 50 de hospitalización.

\section{Caso clínico 3}

Paciente de sexo masculino, producto de embarazo y parto normales, hijo de padres sanos. Presenta síndrome hemolítico urémico a los 9 meses de edad que evoluciona a insu-

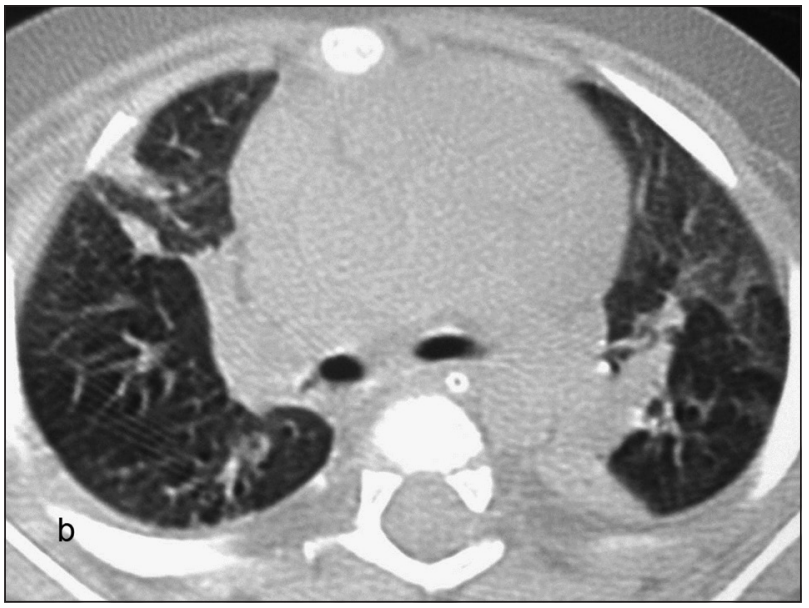

Figura $\mathbf{2 b}$ (paciente $\mathbf{2}$ ). TAC tórax alta resolución (nivel subcarinal): importante disminución de las zonas de vidrio esmerilado. 


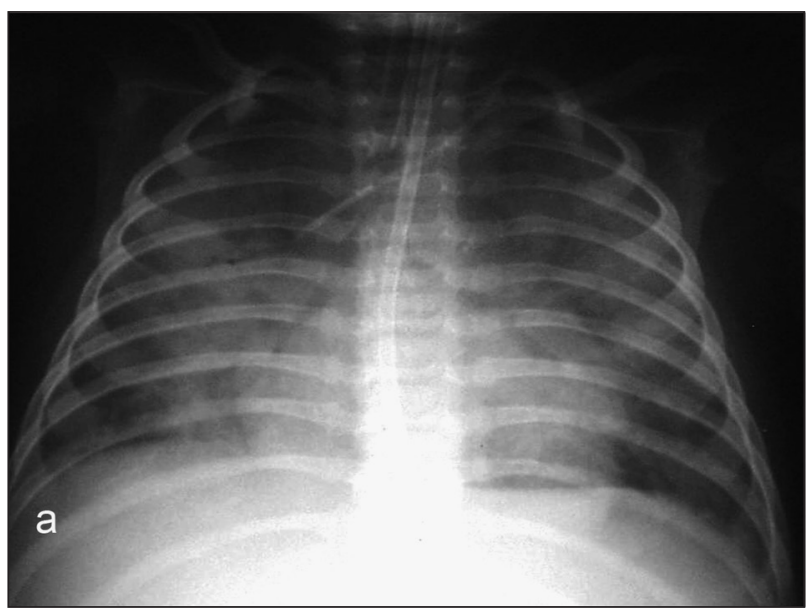

Figura 3a (paciente 4). Rx tórax: imágenes condensantes alvéolointersticiales centrales, basales bilaterales.

ficiencia renal crónica. Se practica trasplante renal donante cadáver a los 2 años de vida, recibe tratamiento inmunosupresor con prednisona, micofenolato y tacrolimus. Controlado en la unidad de broncopulmonar por asma moderada desde los 3 años de edad en tratamiento con budesonida 400 ug/día a permanencia y salbutamol MDI en caso necesario. Evoluciona con una atelectasia crónica del lóbulo inferior izquierdo, por lo que se practica fibrobroncoscopia en 2 oportunidades sin resultado satisfactorio. Presenta una candidiasis esofágica a los 4 años de edad, se administra itraconazol con respuesta exitosa. Se hospitaliza a los 4 años 6 meses de edad luego de un cuadro de 2 días de evolución caracterizado por fiebre alta, tos, disnea, al examen destacaba compromiso del estado general y uso de musculatura accesoria, FR de 45x', frecuencia cardíaca de $140 x^{\prime}$, saturación de $\mathrm{O}_{2}$ de $90 \%$, a la auscultación sibilancias en ambas fases de la respiración, difusas y bilaterales. La Rx de tórax revela focos condensantes múltiples bilaterales, se inicia tratamiento con cloxacilina más ceftriaxona. Durante el segundo día de su internación se realiza LBA que demuestra SV positivo, éste último resultado también se encuentra en orina, se inicia tratamiento con GCV $5 \mathrm{mg} / \mathrm{kg}$ durante 6 semanas con excelente respuesta clínica y radiológica. Se da de alta en buenas condiciones luego de permanecer hospitalizado durante 10 días.

\section{Caso clínico 4}

Lactante varón producto de embarazo, parto y período neonatal normales. Se hospitaliza a los 3 meses de edad por un síndrome diarreico agudo por rotavirus de evolución tórpida, se investiga foco urinario confirmándose una infección urinaria y reflujo vésicoureteral grado II a III. Además presenta desnutrición, se da de alta luego de 12 días de hospitalización. Reingresa a los 15 días con tos, fiebre y compromiso del estado general, que evoluciona a insuficiencia respiratoria parcial, además se sospecha una sepsis, por lo que se administra $\mathrm{O}_{2}$ y cefotaxima, los cultivos para bacterias resultan negativos, la $R x$ tórax muestra imágenes condensantes alvéolo-intersticiales bilaterales, especialmente en ambas bases (Figura 3a). El paciente presenta diarrea prolongada, en tanto el compromiso

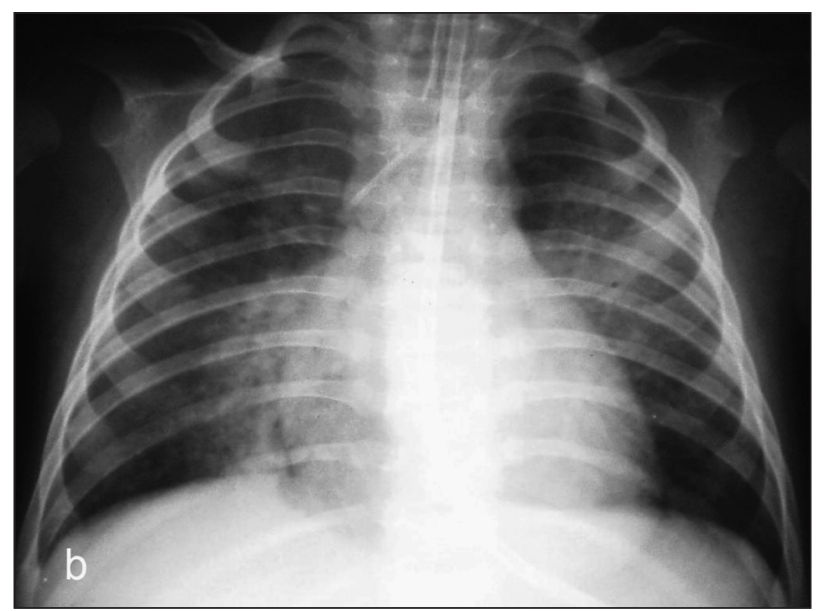

Figura 3b (paciente 4). Rx tórax: disminución de las condensaciones.

respiratorio se hace progresivo, llegando a insuficiencia respiratoria global, la Rx tórax revela un aumento de las imágenes de condensación pulmonar, trasladándose a $\mathrm{UCl}$. El paciente evoluciona grave es conectado a ventilación mecánica con parámetros altos durante 20 días. Se decide solicitar electrolitos en sudor que resultan normales, antigenemia para $\mathrm{VIH}$ es informada como positiva, por lo que se practica SV en secreción bronquial obtenida mediante LBA y en orina y RPC para PJ que también resultan positivos, en consecuencia se inicia terapia antirretroviral, GCV, cotrimoxazol, metilprednisolona e inmunoglobulina, el paciente presenta mejoría clínica y radiológica (Figura $3 b$ ), permanece hospitalizado durante 4 meses. Posteriormente, es controlado ambulatoriamente en el policlínico de infectología, sin embargo, es hospitalizado en múltiples oportunidades debido a numerosos episodios de infecciones respiratorias y digestivas, falleciendo al año y medio de edad.

\section{DISCUSIÓN}

CMV es un virus herpes, endémico, de amplia distribución mundial, con seroprevalencias de 40 a 98\% o más, según edad, distribución geográfica y situación socioeconómica de la población. Esta elevada seropositividad obedece a su alta tasa de transmisión que ocurre por vía vertical, durante el embarazo, parto o lactancia, vía orofaríngea, sexual, transfusiones de hemoderivados y a través del trasplante de órganos ${ }^{(1,2)}$. CMV es el principal agente etiológico del síndrome de $\mathrm{TORCH}$, con una incidencia del $1 \%$ en recién nacidos vivos, pudiendo producir un extenso compromiso sistémico.

La mayoría de las infecciones por CMV se adquieren en los primeros 6 meses de vida( ${ }^{(3-5)}$. Son diversas, pero es más frecuente a nivel pulmonar y su gravedad depende de la edad del individuo susceptible y el estado inmunológico, en especial en aquellos con déficit de la inmunidad celular, independiente de la edad ${ }^{(6-1)}$.

El caso clínico I de nuestra serie presentó neumonía del primer trimestre y síndrome coqueluchoídeo debidos a una 
coinfección por CMV y VRS; Stagno S. y colaboradores describieron este cuadro clínico que se manifiesta en pacientes inmunocompetentes, infectados en el canal del parto o a través de la leche materna, además estos autores encontraron que la tercera parte estaban coinfectados por Chlamydia trachomatis, Pneumocistis jiroveci, Ureaplasma urealíticum, enterovirus u otros virus respiratorios como el VRS (14-16).

Dworsky ME y colaboradores ${ }^{(16)}$ demostraron que la excreción viral comenzaba a las 6-I 4 semanas, lo que coincide con el inicio de los síntomas, que son inespecíficos, los más frecuentemente encontrados fueron taquipnea, tos seca, siendo más característica la coqueluchoídea, ausencia de fiebre, a la auscultación estertores difusos y ausencia de sibilancias. La $R \times$ de tórax evidencia un patrón predominantemente intersticial bilateral, difuso. Todas estas características las presentó nuestra paciente, con la sola excepción de las sibilancias, las que pueden ser atribuidas a la presencia del VRS.

El caso clínico 2 se manifestó como una EPIC, la que ha sido descrita en pacientes inmunocompetentes luego de una neumonía por CMV, también ha sido asociada al virus de Epstein Barr ${ }^{(17)}$. Este cuadro se caracteriza por la persistencia de síntomas respiratorios, aparición de "velcro", dependencia de $\mathrm{O}_{2}$, desde el punto de vista radiológico se observa progresión del patrón intersticial, vidrio esmerilado, presentando buena respuesta a la terapia con corticoides. CMV en el último tiempo ha adquirido mayor importancia debido al aumento de los pacientes inmunodeficientes, lo que se explica por el número creciente de trasplantes, especialmente renal y a la epidemia de SIDA.

El caso clínico 3 presentó una neumonía multifocal por CMV a los 2 años de practicársele un trasplante renal, en terapia inmunosupresora, diagnosticada precozmente con buena respuesta al tratamiento. En los trasplantados renales cerca de un $50 \%$ presenta una primoinfección y el $85 \%$ de ellos el virus recurre, pudiendo causar el rechazo del órgano, lo que se asocia a una disminución de la sobreviva ${ }^{(12,13)}$.

El caso clínico 4 se manifestó como una neumonía de evolución inusual y grave, además presentó un síndrome diarreico prolongado y desnutrición, motivo por el cual se solicitó antigenemia $\mathrm{VIH}$ que resultó positiva, en consecuencia se buscaron agentes oportunistas, aislándose CMV y PJ, los cuales producen infecciones respiratorias indicadoras de SIDA. En una revisión reciente ${ }^{(9)}$ la mayoría de los casos de enfermedad por CMV se produjeron en menores de 6 meses de edad, en el $56 \%$ de estos pacientes fue la enfermedad de debut del SIDA.

En la cohorte Chilena de niños y adolescentes expuestos/ viviendo con $\mathrm{VIH} / \mathrm{SIDA}{ }^{(8)}$ en el $20 \%$ la sospecha de $\mathrm{VIH}$ fue por una infección producida por CMV, en cambio la producida por PJ sólo se encontró en el 2\%. Durante la evolución de esta misma cohorte la infección oportunista que más se detectó fue por CMV en el $41 \%$, especialmente a nivel pulmonar, menos frecuente PJ (7\%). En cuanto a los fallecimientos algo más del $50 \%$ fue por causa infecciosa, el agente más frecuentemente involucrado fue CMV en el $23 \%$ de los fallecidos por neumonía.

Stagno S. y colaboradores ${ }^{(18)}$, revisaron los métodos diagnósticos del CMV, el que clásicamente se hacía en cultivos, donde se puede observar el efecto citopático característico, es decir, células gigantes e inclusiones intranucleares basófilas con halo, pero en la actualidad no es utilizado por ser un método lento. El cultivo acelerado (SV) presenta una alta especificidad y sensibilidad, además es rápido, el resultado se obtiene en 24 a 48 horas, usado especialmente en orina, saliva y en secreción bronquial, obtenida mediante LBA, es la técnica de elección y fue la que empleamos en nuestra serie $^{(18-20)}$.

La antigenemia en sangre también es rápida se obtienen resultados en el plazo de 6 horas, esta técnica al igual que la de SV permite identificar virus con capacidad replicante ${ }^{(18)}$. La RPC es sensible y específica, siendo de gran rapidez en distintas muestras, pero la sola detección del ADN viral no distingue entre virus replicante y en estado latente(18).

La serología que permite identificar lgG e IgM anti CMV no es usada en el diagnóstico, debido a la alta seroprevalencia, su mayor utilidad es poder distinguir entre individuos infectados de no infectados o susceptibles ${ }^{(18)}$, estos últimos tienen un alto riesgo de adquirir la infección, especialmente en condiciones de inmunosupresión, como ocurre en los trasplantes de órganos ${ }^{(12,13)}$. GCV es efectivo en el tratamiento, antes de la introducción de este antiviral la letalidad en inmunosuprimidos era cercana a 100\% Los efectos tóxicos más frecuentes son a nivel hematológico, generalmente reversibles. Además en adultos puede alterar la función renal y hepática, en niños se observan con menor frecuencia ${ }^{(21-23)}$. En nuestra serie lo utilizamos en forma exitosa en 3 pacientes, dos de los cuales eran inmunocomprometidos, no observamos efectos indeseables, en el único caso en que no fue necesario usarlo por buena evolución espontánea, el paciente era inmunocompetente.

Otros antivirales escasamente usados en pediatría son valganciclovir, foscarnet y cidofovir, los que presentan un alto grado de nefrotoxicidad(21). La inmunoglobulina hiperinmune asociada a GCV es útil en la prevención y tratamiento de la enfermedad grave en inmunocomprometidos, especialmente en el trasplante renal y de médula ósea ${ }^{(12,13,23)}$.

\section{REFERENCIAS}

I. Ho M. Citomegalovirus. En: Mandell GL, Douglas G, Bennett J. Enfermedades Infecciosas. Principios y Prácticas. $3^{a}$ ed. Buenos Aires: Editorial Médica Panamericana. 1991; 1222-36.

2. Feigin RD, Cherry JD. Cytomegalovirus. In: Textbook of Pediatric Infectious Diseases. 4a Edition. WB Saunders Company, 1998.

3. Cohen JI, Corey GR. Citomegalovirus infection in the normal host. Medicine 1985; 64: 100.

4. Enright $\mathrm{A}$, Prober $\mathrm{CH}$. Herpesviridae infections in newborns: varicella zoster virus, herpes simplex virus and cytomegalovirus. Pediatr Clin N Am 2004; 51: 889-908.

5. Arav-Boger R, Pass RF. Diagnosis and management of cytomegalovirus infection in the newborn. Pediatr Ann 2002; 31 : 719-25.

6. Mustafa Mahmoud F. Cytomegalovirus infections and disease in the immunocompromised host. Pediatr Infect Dis J 1994; I3: 249-59.

7. Brockmann P, Viviani T, Peña A. Compromiso pulmonar en la infección por virus de inmunodeficiencia humana en niños. Rev Chil Infect 2007; 24: 301-5. 
8. Comité Nacional de VIH/SIDA Pediátrico, Sociedad Chilena de Pediatría: Cohorte Chilena de Niños y Adolescentes Expuestos/ Viviendo con VIH/SIDA, 3er Informe 2005-2006.

9. Peña A, Larrañaga C, Luchsinger V, Villarroel J, Chávez A, Wu E. y Comité Nacional de SIDA Pediátrico Sociedad Chilena de Pediatría. Enfermedad por citomegalovirus en niños chilenos infectados por el virus de la inmunodeficiencia humana- I. Rev Chil Infect 2007; 24: 477-84.

10. Kattan M, Platzker A, Mellins RB, Schluchter MD, Chen XC, Peavy $\mathrm{H}$, et al. Respiratory diseases in the first year of life in children born to HIV-I -infected women. Pediatr Pulmonol 200 I ; 31 : 267-76.

II. Graham SM, Gibb DM. HIV disease and respiratory infection in children. Br Med Bull 2002; 61: 131-50.

12. Van der Bij W. Management of cytomegalovirus infection and disease after solid organ transplantation. Clin Infect Dis 200 I; 33 Suppl I: S32-7.

13. Razonable RR, Paya CV, Smith TF. Minireview. Role of laboratory in diagnosis and management of cytomegalovirus infection in hematopoietic stem cell and solid-organ transplant recipients. J Clin Microbiol 2002; 40: 746-52.

14. Stagno S, Reynolds DW, Pass RF, Alford CA. Breast milk and the risk of cytomegalovirus infection. N Engl J Med 1980; 102: 1073-6.

15. Stagno S, Brasfield DM, Brown MB, et al. Infant pneumonitis associated with cytomegalovirus, chlamydia, pneumocystis, and ureaplasma: a prospective study. Pediatrics 1981; 68: 322-9.
16. Dworsky ME, Stagno S. Newer agents causing pneumonitis in early infancy. Pediatr Infect Dis 1982; I: 1 88-95.

17. Fan LL, Deterding RR, Langston C. Pediatric Interstitial Lung Disease Revisited. State of the Art. Pediatr Pulmonol 2004; 38: 369-78.

18. Stagno S, Brito W, Pass R. Cytomegalovirus. En: Schmidt N, Emmons R. Diagnostic procedures for viral, rickettsial and chlamydial infections. 6a ed. Washington: American Public Health Ass 1989; 321-78.

19. Gleaves CA, Smith TF, Shuster EA, Pearson GR. Rapid detection of cytomegalovirus in MRC-5 cells inoculated with urine specimens by using low-speed centrifugation and monoclonal antibody to an early antigen. J Clin Microbiol 1984; 19: 917.

20. Jespersen DJ, Drew WL, Gleaves CA et al. Multisite evaluation of a monoclonal antibody reagent for rapid diagnosis of cytomegalovirus in the shell vial assay in BAL. J Clin Microbiol 1989; 27: 1502-9.

21. De Clercq E. Antiviral drugs in current clinical use. J Clin Virol 2004. 30: II 5-33.

22. Arancibia ME, Cordero J. Tratamiento con ganciclovir en neumonía intersticial por citomegalovirus. Rev Chil Pediatr 1993; 64: 24I-4.

23. Ljungman P, Engelhard D, Link H, Biron P. Treatment of interstitial pneumonitis due to cytomegalovirus with ganciclovir and intravenous immune globulin: experience of European Bone Marrow Transplant Group. Clin Infect Dis 1992; 14: 831-5. 